\title{
Input-Output and Integrated Models for Demo-Economic Impact Analysis-an Empirical Comparison
}

\author{
GUY R. WEST \\ Regional and Urban Economics Research Unit, Department of Economics, \\ University of Queensland, Queensland 4072, Australia
}

\begin{abstract}
QUIP is an integrated input-output + economitric model of the Queensland economy. It was designed to replace the conventional input-output model for analysing economic impacts at the state level. Therefore it is pertinent to compare the results from the two types of models as an aid in the understanding and interpretation of the results. In general, the integrated model will produce smaller aggregate impacts than the closed input-output model in a static context (because of the use of marginal rather than average primary factor and household coefficients), but at a disaggregated industry level, it tends to redistribute the flow-ons from the service type industries to manufacturing type industries which have more rigid production structures. In a dynamic context, the input-output model misses the flow-through effects on the economy in later time periods through demographic changes. The integrated model shows that these flow-through effects are substantial and can more than double the size of the short-run multipliers.
\end{abstract}

Keywords : Demo-economic Impacts, Input-output, Intergrated model, Tourism

\section{Introduction}

The Queensland Impact and Projection Model (QUIP) represents a second generation integrated input-output + econometric model of Queensland. The first generation, termed QIM (West 1991), was constructed as an experimental project. QUIP uses an updated database and input-output table in addition to major respecifications and extensions, and represents a major step forward over QIM, both theoretically and empirically.

The object in this paper is to compare empirically the QUIP model with its main competitor, the conventional input-output (IO) model. Input-output analysis is still the most widespread method for measuring impacts at the regional and disaggregated industry level in Australia. Possible alternatives are regional econometric or computable general equilibrium (CGE) models, but these are few and far between at the regional level in Australia. Econometric models are generally forecasting oriented and lack the sectoral disaggregation of the input-output model, while the CGE model suffers from regional data problems. The CGE model also imposes more rigid theoretical (neo-classical) structures in an optimisation framework, whereas the econometric model simply tracks the economy as it appears. 
Nevertheless, there is a demand for more sophisticated regional models, and integrated models are providing one avenue of development.

\section{The Queensland Integrated Model - The Household Sector}

There are many modelling techniques available in economics. No single methodology can be regarded as providing a complete answer to all questions posed by the analyst, with each method exhibiting a different set of characteristics. Integrated models recognise this fact, and attempt to splice the different approaches in such a way as to enhance the strengths and reduce the weaknesses. QUIP specifically addresses the demo-economic integration of regional input-output and econometric methods as applied to the Queensland economy.

QUIP is an integrated model of the IO + E type. An IO + E type model has an input-output model as its central core and endogenises some elements of factor inputs and final demand with econometric relationships. The aim is to incorporate the detailed sectoral desaggregation of the input-output system within a (non-linear) dynamic and extended framework. QUIP is not a forecasting model as such ; rather it retains the impact modelling structure of the input-output model, but is extended to include medium-term dynamic impacts and projections. In addition, other variables of interest not included in the simple inputoutput model are estimated, such as other (non-wage) income, labour force and demographic indicators.

The assumptions of the input-output model are concerned almost entirely with the nature of production as conventionally defined. The model is based on the premise that it is possible to divide all productive activities in an economy into sectors or industries whose interrelations can be meaningfully expressed as a set of input equations :

$$
\mathbf{A x}+\mathbf{y}=\mathbf{x}
$$

Where $\mathbf{x}$ is a $n \times 1$ vector of industry output levels, $\mathbf{A}$ is an $n \times n$ matrix of input coefficients, $a_{i j}$, representing the amount purchased by industry $j$ from industry $i$ per unit of output of industry $j$, and $\mathbf{y}$ is a $n \times 1$ vector of exogenous final demands by industry. The crucial assumption is that the money value of goods and services delivered by an industry to other producing sectors (including households) is a linear and homogeneous function of the output level of the purchasing industry.

This assumption of linearity is, however, a valid criticism of the simple input-output model in many instances. It may by acceptable for some producing industries, but has been shown to be particularly invalid for the household sector. For example, the IO model's household income and expenditure coefficients represent average propensities and the employment coefficients reflect average labour productivity rates, yet many industries can increase output in the short term without corresponding proportional increases in wage costs 
and employment. Similarly, an increase in household income may not lead to corresponding short term proportional changes in household expenditure. The operation of the model must be improved if changes in employment, income and subsequent household expenditure are estimated as more realistic (marginal) functions of output or value added.

In addition, the integrated model recognises that short-run disequilibrium adjustments can occur after a shock to the economy. The dynamic structure of the model enables these temporal adjustments to be studied to give a greater understanding of the real impacts on the economy. For example, a major develoyment project draws on the local workforce, resulting in a reduction in local unemployment levels. This will attract workers and families (i. e. net migration) into the region, but subject to a lag process, increasing the local labour force and population. Provided the development project is sustained, the net benefits should continue with additional multiplier effects which are demographically driven, reinforced by subsequent demands for increased infrastructure and service facilities. But if the project terminates, unemployment levels will suddenly rise to levels higher than those before the project started and, until the population levels can adjust (through out-migration), or other projects move in to take the place of the terminated project, there will be a reduction in benefits which could result in a net loss to the local economy.

The basic difference between the IO model and the IO $+\mathrm{E}$ model is the closure mechanism from primary factor inputs to final demand. In QUIP, this closure focuses on the household sector. Figure 1 demonstrates the difference between the two models. The conventional closed IO model, as shown in Figure la, endogenises households by assuming all consuming households are homogeneous and employed, with wage income being the only household income. Therefore, if there is a stimulus to the economy, the only place where industries can draw labour is from outside the region (in-migration). This draw-back has led to the development of a number of so-called demo-economic models, the most notable being the Batey and Madden type activity-commodity extended input-output model (e. g. Batey and Madden (1981) ; Batey, Madden and Weeks (1987)). However, these models have failed to achieve wide-spread use, probably due to the retained linearity structure.

The integrated model, on the other hand, allows for the possibility of unemployed and economically inactive households which still consume local goods and services, thus contributing to local economic activity, and which can shift to the employed pool in response to an economic stimulus or growth. Other non-wage income, such as distributed profits, social security payments, etc. are also included, as well as population growth over time, both natural and induced.

As shown in Figure $\mathrm{lb}$, the household sector has been replaced by a number of blocks ; in particular labour, income, demographic and household expenditure. Rather than a simple proportional relationship between wages and household expenditure, the relationships within 
Figure 1. Structural Differences between Input-Output and Integrated Models

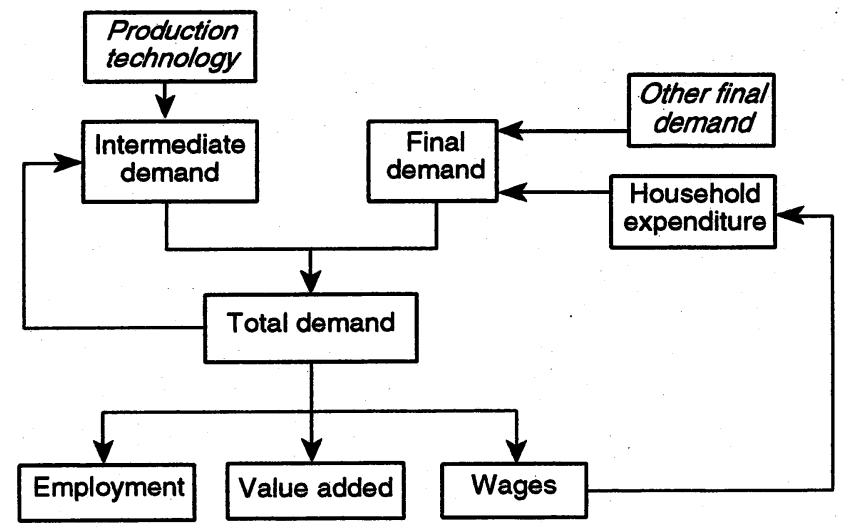

Figure 1a. Input-Output Model

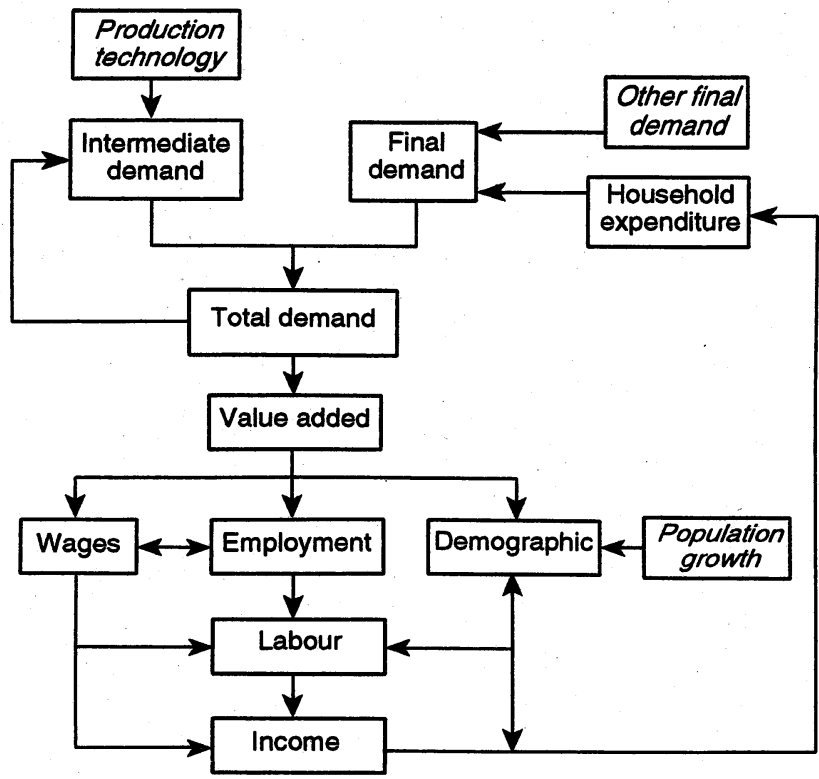

Figure 1b. Integrated Model

and between each block are estimated econometrically. All sectoral relationships are derived from value added, which determines the sectoral levels of wages and salaries and employment. Total gross regional product also provides an input into the demographic block which calculates various population related variables.

Total wages and salaries, employment and population statistics feed into the labour block. This calculates the total labour force, unemployment level and the number receiving some 


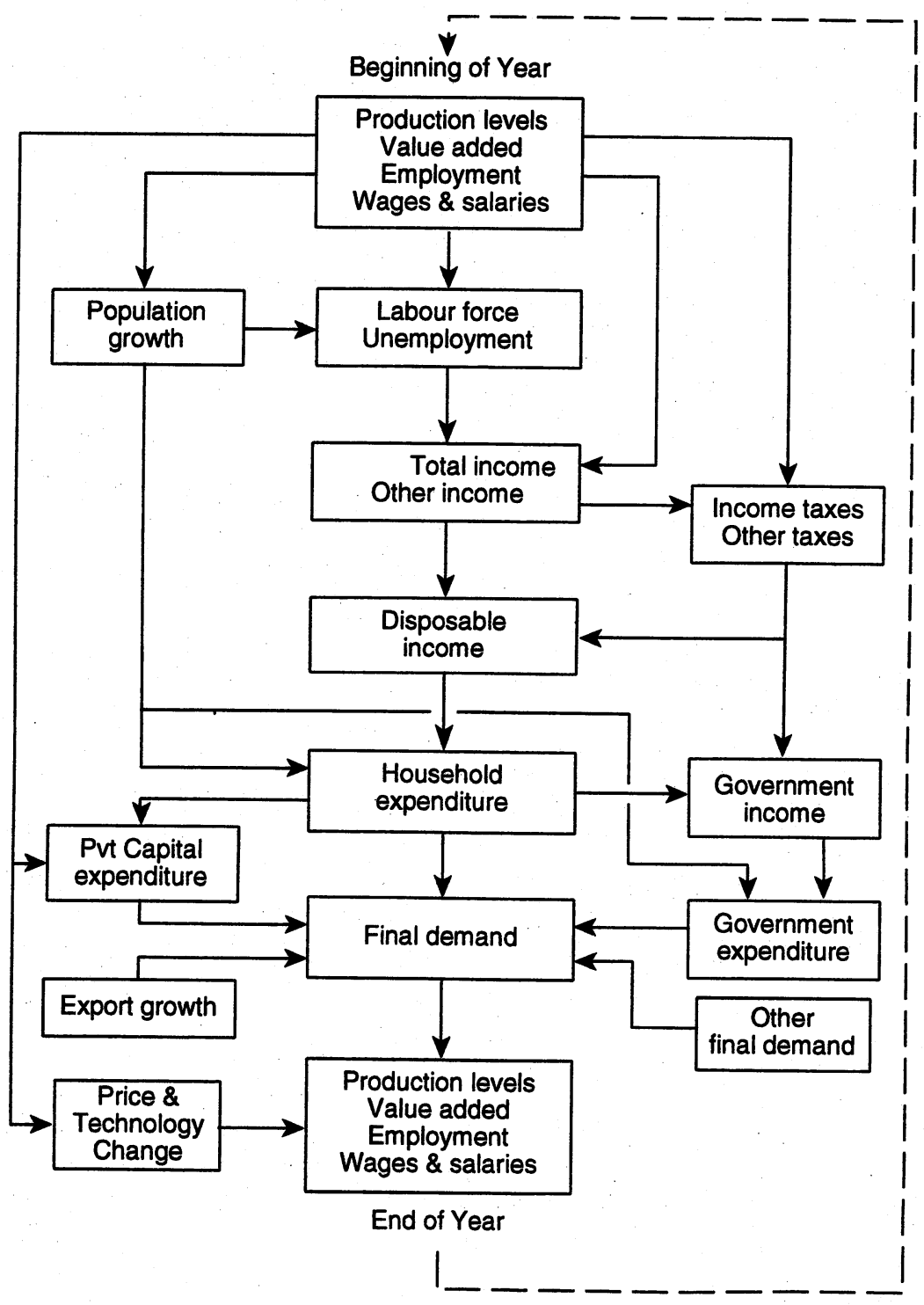

Figure 2. Overview of QUIP

form of government benefits including social security and unemployment benefits. These are required for the income block which calculates total income, income taxes and other taxes and deductions, and hence total disposable income. This is used to estimate total household expenditure which, in turn, is used to estimate a set of demand functions by eight major commodity groups. These are transformed into household expenditure by industry category to provide the private consumption expenditure component of final demand. 
West

Table 1 Industrial Sectors

\begin{tabular}{cl}
\hline Sector No. & \multicolumn{1}{c}{ Sector Name } \\
\hline 1 & Agriculture, Forestry and Fishing \\
2 & Mining \\
3 & Food Manufacturing \\
4 & Wood and Paper Manufacturing \\
5 & Machinery, Appliances and Equipment \\
6 & Metal Products \\
7 & Non-Metallic Mineral Products \\
8 & Other Manufacturing n. e. c. \\
9 & Electricity, Gas and Water \\
10 & Building and Construction \\
11 & Wholesale and Retail Trade \\
12 & Transport and Communication \\
13 & Finance and Business Services \\
14 & Public Administration, Defence and Community Services \\
15 & Recreation, Personal and Other Services \\
\hline
\end{tabular}

n. e. c. : not elsewhere classified

Supplementary blocks include the government and price blocks. The government block estimates State Government revenue and expenditure which also comprises a part of final demand. The price block estimates industry price changes in a manner similar to that employed in CGE models. These are used to update the intermediate input coefficients for relative price changes, with subsequent balancing adjustments taking account of any technological change in the coefficients (Bulmer-Thomas (1982)). In the application in this paper, however, the emphasis is on the demo-economic characteristics of the model - the government and investment components of final demand are exogenously determined as they are in the conventional input-output model. Other final demand is projected independently and this is normally where impacts are introduced as per the usual input-output model.

Figure 2 provides a schematic representation of QUIP. The 15 industrial sectors in the model are given in Table 1. The choice of sectors is determined by the availability of a consistent set of time-series data for a number of variables at the sectoral level, such as value added, wages and salaries and employment. The input-output table is based on an updated version of the Queensland table for 1985-86 form the Queensland Government Statistician's Office (1990). This also determines the base year of the model, i. e. the model is calibrated to $1985-86$ and all variables are measured in constant $1985-86$ values.

Overall, the model contains 115 equations. Because the econometric equations have dynamic specifications, the model is driven forward on an annual basis, thus tracking the economy over the projected time period. For a detailed description of the structural equations and estimation technique, see West (1994). 
Input-Output and Integrated Models for Demo-Economic Impact Analysis-an Empirical Comparison

Table 2 Visitor Expenditures in Queensland, 1985-86 to 1990 $-91, \$ m^{a}$

\begin{tabular}{ccccc}
\hline Year & Intrastate & Interstate & Overseas & Total \\
\hline $1985-86$ & 442.67 & 568.84 & 148.05 & $1,159.56$ \\
$1986-87$ & 430.46 & 716.22 & 196.49 & $1,343.17$ \\
$1987-88$ & 477.04 & 834.26 & 401.88 & $1,713.18$ \\
$1988-89$ & 445.14 & 947.66 & $596.32^{\mathrm{b}}$ & $1,989.12$ \\
$1989-90$ & 603.47 & $750.70^{\mathrm{c}}$ & 510.65 & $1,864.82$ \\
$1990-91$ & 619.11 & 972.60 & 520.89 & $2,112.60$ \\
\hline
\end{tabular}

Source: Queensland Tourist and Travel Corporation, and National Centre for Studies in Travel and Tourism.

${ }^{a}$ All values in 1985-86 millions Australian dollars (AUD).

bWorld Expo '88.

'Domestic airline dispute.

\section{Impact Analysis}

Tourism is an important and integral part of the Queensland economy. There has been strong growth in tourism activity over the last decade, with large increases in visitor numbers, tourist spending and investment. The economic analysis of tourism at the regional level in Australia has traditionally been handled in an input-output framework (e. g. Hundloe et al. (1981) ; Powell et al. (1987) ; West and Bayne (1990)). Archer (1977) and Fletcher (1989) are two of many who describe the use of input-output for measuring the economic impact of tourism expenditures.

Both the input-output model and the integrated model provide a platform for analysing the impact of tourism activity on the Queensland economy. Visitor expenditure analysis provides the ideal situation for the comparison of the two models since the expenditures are classified as final demand (final consumption expenditure of visitors). While it is possible to measure the impact of existing industries within the intermediate quadrant, this produces a less direct comparison because the analysis is, by necessity, handled differently in the two models. Changes in final demand, however, are handled identically in each model and therefore the results are directly comparable.

The aim is to estimate the impact of visitors who stay in commercial accommodation in Queensland in 1990-91 on the Queensland economy. The scenario modelled is intended to be representative of current trends, and expenditures by intrastate, interstate and overseas visitors during the period 1985-86 to 1990-91 are shown in Table 2. The expenditure data, obtained from the Queensland Tourist and Travel Corporation's Queensland Visitor Survey, have been deflated to $1985-86$ values, allocated to industry sectors and converted to basic values in order to be consistent with the 1985-86 input-output table used in QUIP. The same 
input-output table is used for measuring the conventional input-output impacts. In QUIP, the model is run twice ; first without the exogenous tourist expenditures to obtain the base level projections, and second with the tourist expenditures. The difference provides a measure of the impact of exogenous tourist expenditures on the economy. After 1990-91, the tourist expenditures are assumed to cease. All results are expressed in 1985-86 values for consistency.

\subsection{Aggregate Short-Run Impacts}

The aggregate results of visitor expenditures on gross output, gross state product, wages and salaries and employment for the two models are shown in Table 3. It can be seen that for all three visitor categories, the impacts from the input-output model are greater than the short-run impacts from the integrated model. This is expected because of the use of marginal household relationships in the integrated model, and adjustments to the labour force (and other population variables) have not had time to occur. The short-run impact refers to the impact on the economy which occurs in the same year as the impacting agent (here 1990-91), but ignores the flow-through effects in later time periods. It is assumed here that the flow-on effects obtained from the simple input-output model also occur in the same 12 month period. Gross state product estimates differ by $\$ 5.47$ millinon(1.0\%) for intrastate tourists to $\$ 15.26$ million (1.8\%) for interstate visitors. The input-output model overestimates wages and salaries impacts by $\$ 27.35$ million (9.4\%) for intrastate to $\$ 58.57$ million (13.1\%) for interstate tourists, and employment by 5.36 thousand (32.1\%) to 11.77 thousand (39.4\%) for overseas and interstate visitors respectively.

The conventional multiplier values are also provided in Table 3, but it must by remembered that the multiplier values from the integrated model are not constant. Unlike the IO model, in which the multiplier value is the same for all multiples of the initial impact, the multiplier values from the integrated model vary with the size of the initial impact. Small changes in final demand will tend to have smaller multiplier effects than large changes in final demand. The important thing to consider in impact studies is not the size of the multiplier but the magnitude of the total effect on value added, wages and salaries and employment.

The total impacts shown in Table 3 represent the aggregate impact by all three categories of visitors. It comprises the summation of the separate categories for the input-output model but not for the integrated model since the components are not additive due to the marginal relationships, as explained above. The total impacts obtained from QUIP are threrfore slightly less than the summation of the separate impacts. In many ways, different types of tourists are not distinguishable from each other, resulting in overlapping effects of servicing visitors' needs. It can be seen that the input-output model 'overestimates' the total (short-run) 
Input-Output and Integrated Models for Demo-Economic Impact Analysis-an Empirical Comparison

Table 3 Comparison of Aggregate Short-Run Impacts, 1990-91

\begin{tabular}{lr|rr|rr|r}
\hline & \multicolumn{1}{c}{$\begin{array}{l}\text { Initial } \\
\text { Shock }\end{array}$} & \multicolumn{1}{c}{$\begin{array}{c}\text { IO } \\
\text { Impact }\end{array}$} & Multiplier & $\begin{array}{r}\text { QUIP } \\
\text { Impact }\end{array}$ Multiplier Difference \\
\hline Intrastate & & & & & & \\
Output & 619.11 & $1,350.36$ & 2.18 & $1,287.90$ & 2.08 & 62.46 \\
GSP & 249.42 & 555.76 & 2.23 & 550.29 & 2.21 & 5.47 \\
Wages & 145.68 & 319.06 & 2.19 & 291.71 & 2.00 & 27.35 \\
Employment & 13.34 & 26.41 & 1.98 & 20.14 & 1.51 & 6.27 \\
\hline Interstate & & & & & & \\
Output & 972.60 & $2,110.59$ & 2.17 & $2,003.74$ & 2.06 & 106.85 \\
GSP & 400.76 & 876.22 & 2.19 & 860.96 & 2.15 & 15.26 \\
Wages & 233.68 & 505.03 & 2.16 & 446.46 & 1.91 & 58.57 \\
Employment & 21.29 & 41.66 & 1.96 & 29.89 & 1.40 & 11.77 \\
\hline Overseas & & & & & & \\
Output & 520.89 & $1,117.36$ & 2.15 & $1,049.90$ & 2.02 & 67.46 \\
GSP & 218.25 & 467.33 & 2.14 & 454.90 & 2.08 & 12.43 \\
Wages & 126.41 & 269.67 & 2.13 & 241.37 & 1.91 & 28.30 \\
Employment & 11.47 & 22.05 & 1.92 & 16.69 & 1.46 & 5.36 \\
\hline Total & & & & & & \\
Output & $2,112.60$ & $4,578.31$ & 2.17 & $4,338.13$ & 2.05 & 240.18 \\
GSP & 868.43 & $1,899.31$ & 2.19 & $1,864.59$ & 2.15 & 34.72 \\
Wages & 505.77 & $1,093.76$ & 2.16 & 976.76 & 1.93 & 117.00 \\
Employment & 46.10 & 90.12 & 1.96 & 66.61 & 1.44 & 23.51 \\
\hline Dollar values & & & & & & \\
\hline
\end{tabular}

Dollar values in 1985-86 millions AUD, employment in thousands.

Multiplier values per unit change in final demand (visitor expenditure)

impact on gross state product by $\$ 34.72$ million (1.9\%), wages and salaries by $\$ 117.00$ million (12.0\%) and employment by a massive 23.51 thousand (35.3\%). The proportion of gross state product taken up by wages and salaries decreases from $57.6 \%$ with the input-output model to $52.4 \%$ with the integrated model, reflecting the capacity of industry to increase production without corresponding proportional increases in labour costs and employment.

\subsection{Disaggregated Short-Run Impacts}

Tables 4, 5 and 6 give the disaggregated impacts across the industrial sectors for gross state product, wages and salaries and employment respectively for each of the two models. Disaggregated output impacts are not considered in this section because of the limited usefulness of output effects in impact analysis. Output effects are difficult to interpret because of possible double counting. The most obvious point to note is that, despite the lower overall impacts from the integrated model, a comparison of the distributions of the impacts from the two models does not display a similarly consistent pattern. By referring to Table 
West

Table 4 Disaggregated Short-Run Gross State Product Impacts, 1990-91, \$m

\begin{tabular}{|c|c|c|c|c|c|c|c|c|}
\hline \multirow[b]{2}{*}{ Sector } & \multicolumn{4}{|c|}{ IO } & \multicolumn{4}{|c|}{ QUIP } \\
\hline & $\begin{array}{l}\text { Intra } \\
\text { state }\end{array}$ & $\begin{array}{l}\text { Inter } \\
\text { state }\end{array}$ & $\begin{array}{l}\text { Over } \\
\text { seas }\end{array}$ & Total & $\begin{array}{l}\text { Intra } \\
\text { state }\end{array}$ & $\begin{array}{l}\text { Inter } \\
\text { state }\end{array}$ & $\begin{array}{l}\text { Over } \\
\text { seas }\end{array}$ & Total \\
\hline 1 & 45.47 & 66.96 & 30.18 & 142.61 & 43.51 & 63.71 & 28.32 & 135.46 \\
\hline 2 & 15.21 & 21.15 & 13.38 & 49.74 & 17.78 & 24.27 & 15.67 & 57.70 \\
\hline 3 & 46.92 & 68.08 & 28.72 & 143.72 & 47.91 & 68.75 & 28.77 & 145.55 \\
\hline 4 & 9.56 & 14.86 & 7.90 & 32.32 & 12.40 & 18.72 & 9.80 & 40.82 \\
\hline 5 & 3.29 & 5.51 & 3.01 & 11.81 & 4.87 & 7.63 & 4.09 & 16.48 \\
\hline 6 & 2.54 & 3.92 & 2.02 & 8.48 & 4.61 & 6.63 & 3.47 & 14.52 \\
\hline 7 & 1.70 & 2.59 & 1.28 & 5.57 & 2.49 & 3.63 & 1.82 & 7.87 \\
\hline 8 & 29.49 & 39.40 & 26.54 & 95.43 & 29.40 & 38.76 & 26.08 & 94.38 \\
\hline 9 & 19.45 & 30.50 & 16.10 & 66.05 & 17.79 & 27.72 & 14.34 & 59.78 \\
\hline 10 & 4.33 & 7.18 & 3.84 & 15.35 & 3.83 & 6.36 & 3.37 & 13.55 \\
\hline 11 & 125.47 & 184.12 & 104.52 & 414.11 & 122.37 & 178.16 & 99.91 & 399.96 \\
\hline 12 & 45.93 & 96.41 & 55.64 & 197.98 & 41.94 & 89.63 & 51.75 & 183.23 \\
\hline 13 & 33.60 & 53.13 & 28.38 & 115.11 & 25.12 & 39.58 & 20.57 & 85.17 \\
\hline 14 & 21.86 & 34.46 & 18.37 & 74.69 & 24.40 & 38.11 & 19.41 & 81.68 \\
\hline 15 & 150.96 & 247.95 & 127.45 & 526.36 & 151.86 & 249.25 & 127.52 & 528.47 \\
\hline
\end{tabular}

Table 5 Disaggregated Short-Run Wage and Salary Impacts, 1990-91, \$m

\begin{tabular}{|c|c|c|c|c|c|c|c|c|}
\hline \multirow[b]{2}{*}{ Sector } & \multicolumn{4}{|c|}{ IO } & \multicolumn{4}{|c|}{ QUIP } \\
\hline & $\begin{array}{l}\text { Intra } \\
\text { state }\end{array}$ & $\begin{array}{l}\text { Inter } \\
\text { state }\end{array}$ & $\begin{array}{l}\text { Over } \\
\text { seas }\end{array}$ & Total & $\begin{array}{l}\text { Intra } \\
\text { state }\end{array}$ & $\begin{array}{l}\text { Inter } \\
\text { state }\end{array}$ & $\begin{array}{l}\text { Over } \\
\text { seas }\end{array}$ & Total \\
\hline 1 & 12.37 & 18.22 & 8.21 & 38.80 & 10.93 & 15.59 & 7.10 & 33.54 \\
\hline 2 & 4.80 & 6.68 & 4.23 & 15.71 & 5.18 & 6.90 & 4.56 & 16.59 \\
\hline 3 & 28.52 & 41.39 & 17.46 & 87.37 & 26.89 & 37.59 & 16.11 & 80.52 \\
\hline 4 & 7.51 & 11.69 & 6.21 & 25.41 & 9.00 & 13.24 & 7.10 & 29.20 \\
\hline 5 & 2.44 & 4.09 & 2.23 & 8.76 & 3.34 & 5.10 & 2.80 & 11.14 \\
\hline 6 & 1.40 & 2.16 & 1.11 & 4.67 & 2.34 & 3.28 & 1.76 & 7.27 \\
\hline 7 & 0.76 & 1.16 & 0.57 & 2.49 & 1.03 & 1.46 & 0.75 & 3.21 \\
\hline 8 & 13.44 & 17.95 & 12.09 & 43.48 & 12.37 & 15.88 & 10.95 & 39.13 \\
\hline 9 & 6.67 & 10.45 & 5.52 & 22.64 & 5.63 & 8.55 & 4.53 & 18.65 \\
\hline 10 & 2.82 & 4.68 & 2.50 & 10.00 & 2.30 & 3.73 & 2.02 & 8.03 \\
\hline 11 & 76.33 & 112.01 & 63.59 & 251.93 & 68.72 & 97.48 & 56.00 & 221.41 \\
\hline 12 & 25.17 & 52.84 & 30.50 & 108.51 & 21.22 & 44.21 & 26.14 & 91.40 \\
\hline 13 & 26.98 & 42.67 & 22.80 & 92.45 & 18.62 & 28.59 & 15.22 & 62.25 \\
\hline 14 & 20.83 & 32.83 & 17.50 & 71.16 & 21.46 & 32.66 & 17.04 & 70.82 \\
\hline 15 & 89.02 & 146.22 & 75.16 & 310.40 & 82.67 & 132.21 & 69.29 & 283.61 \\
\hline
\end{tabular}

4, for example, it can be seen that the integrated model generally results in higher impacts in the manufacturing sectors and lower impacts in the service sectors. Moreover, the sector by sector differences are much greater than the overall difference. Even though the overall 
Input-Output and Integrated Models for Demo-Economic Impact Analysis-an Empirical Comparison

Table 6 Disaggregated Short-Run Employment Impacts, 1990-91, ('000)

\begin{tabular}{|c|c|c|c|c|c|c|c|c|}
\hline \multirow[b]{2}{*}{ Sector } & \multicolumn{4}{|c|}{ IO } & \multicolumn{4}{|c|}{ QUIP } \\
\hline & $\begin{array}{l}\text { Intra } \\
\text { state }\end{array}$ & $\begin{array}{l}\text { Inter } \\
\text { state }\end{array}$ & $\begin{array}{l}\text { Over } \\
\text { seas }\end{array}$ & Total & $\begin{array}{l}\text { Intra } \\
\text { state }\end{array}$ & $\begin{array}{l}\text { Inter } \\
\text { state }\end{array}$ & $\begin{array}{l}\text { Over } \\
\text { seas }\end{array}$ & Total \\
\hline 1 & 2.23 & 3.29 & 1.48 & 7.00 & 1.66 & 2.29 & 1.09 & 5.04 \\
\hline 2 & 0.11 & 0.16 & 0.10 & 0.37 & 0.10 & 0.13 & 0.09 & 0.33 \\
\hline 3 & 1.49 & 2.16 & 0.91 & 4.56 & 1.26 & 1.72 & 0.77 & 3.75 \\
\hline 4 & 0.47 & 0.73 & 0.39 & 1.59 & 0.47 & 0.67 & 0.38 & 1.52 \\
\hline 5 & 0.12 & 0.20 & 0.11 & 0.43 & 0.16 & 0.23 & 0.13 & 0.52 \\
\hline 6 & 0.06 & 0.10 & 0.05 & 0.21 & 0.10 & 0.14 & 0.08 & 0.32 \\
\hline 7 & 0.04 & 0.07 & 0.03 & 0.14 & 0.04 & 0.06 & 0.03 & 0.14 \\
\hline 8 & 0.85 & 1.14 & 0.77 & 2.76 & 0.49 & 0.61 & 0.44 & 1.52 \\
\hline 9 & 0.28 & 0.44 & 0.23 & 0.95 & 0.20 & 0.29 & 0.16 & 0.65 \\
\hline 10 & 0.14 & 0.23 & 0.12 & 0.49 & 0.09 & 0.15 & 0.08 & 0.33 \\
\hline 11 & 6.72 & 9.86 & 5.60 & 22.18 & 5.09 & 6.99 & 4.20 & 16.22 \\
\hline 12 & 1.46 & 3.06 & 1.76 & 6.28 & 1.03 & 2.09 & 1.28 & 4.40 \\
\hline 13 & 1.75 & 2.77 & 1.48 & 6.00 & 1.02 & 1.51 & 0.84 & 3.36 \\
\hline 14 & .1 .06 & 1.68 & 0.89 & 3.63 & 0.92 & 1.36 & 0.74 & 3.01 \\
\hline 15 & 9.62 & 15.80 & 8.12 & 33.54 & 7.51 & 11.64 & 6.37 & 25.50 \\
\hline
\end{tabular}

difference in gross state product is only 1.9 per cent, five sectors show individual differences of over 20 per cent, these being sector 13 (Finance and business services) where the contribution to gross state product from the input-output model is over 35 per cent greater than that from the integrated model, and sectors 4 to 7 (Wood and paper manufacturing; Machinery, appliances and equipment ; Metal products ; and Non-metallic mineral products) which have significantly higher impacts under the integrated model.

The differences become greater with wages and salaries and employment. Six sectors have wage differences greater than 20 per cent. Sectors 13 (Finance and business services), 9 (Electricity, gas and water) and 10 (Building and construction) have significantly lower wage impacts with the integrated model, while sectors 5, 6 and 7 (Machinery, appliances and equipment ; Metal products ; and Non-metallic mineral products) have significantly higher wage impacts. Employment, as is expected, has consistently lower impacts from the integrated model, the exceptions being sectors 5 (Machinery, appliances and equipment) and 6 (Metal products). These results imply that the service type industries are better able to support the increase in tourist activity largely within their existing resources, whereas manufacturing type industries, which have more rigid production structures, respond in a manner closer to that of the Leontief production system.

The general patterns of the impacts correspond more or less with expectations. Recreational activity takes the greates share of the generated gross state product, wage and employment effects, with Trade second. Overseas and interstate visitors contribute a 
relatively larger proportion to the Recreation sector than intrastate visitors. The proportion of flow-ons to the Transport sector are greatest from overseas visitors and lowest for intrastate tourists because a larger proportion of local tourists provide their own transportation. Similarly, the proportion of the flow-on effects to the Trade and Food manufacturing sectors is greater for intrastate tourists since local holiday makers tend to purchase many commodities, such as food, etc., through local trade outlets rather than through hotels, clubs and resorts which make up a large part of the Recreation sector.

\subsection{Long-Run Impacts}

The input-output model, in its simple form, is a static model. It does not take account of possible dynamic flow-through effects to later time periods, primarily through demographic change, but also through technological change, investment and export growth. Therefore the flow-on effects reported from an input-output model will generally underestimate the true long-run impacts to some degree.

Table 7 gives the QUIP estimated impacts on gross output, gross regional product, wages and salaries and employment to the year 1999-2000. It can be seen that the flow-on effects after 1990-91 are more than double those experienced in the initial period, primarily due to the demographic induced effects. The cumulative impact on the Queensland economy amounts to $\$ 9,550.45$ million in output, $\$ 4,112.95$ million to gross state product, $\$ 2,286.01$ million in wage and salary payments, and 171.65 thousand employed. The dynamic or long-run multipliers, compared to the static or short-run multipliers in Table 3 , are now 4.52 for output, 4.74 for gross regional product, 4.52 for wages and salaries, and 3.72 for employment. In this case, it can be seen that the additional flow-through impacts in later periods are substantial.

The distribution of these long-run impacts is also of interest. Whereas the short-run impacts are felt mainly in those sectors experiencing the primary final demand shocks, in the longer term they will tend to disseminate more evenly throughtout the economy in response to the general growth in 'people-oriented' infrastructure and services required to support the increased population.

Figures 3 to 5 show the growth and decline paths of some of the major variables. Figure 3 shows the change in output and gross state product from the base year until it reaches a peak in 1990-91. After the initial tourist expenditures cease, there is a drop before stabilising and gradually approaching zero towards the end of the decade. The rate of decline in the decay function is determined by the relative growth rates of the exogenous variables (e. $g$. exports) and the exogenous shock, and the length of the lag structure in the model ${ }^{1}$. Prior to $1990-91$, the average growth rate in the exogenous series was 13.7 per cent per annum (4.9 per cent per annum excluding tourist expenditures). After 1990-91, the average annual 
Input-Output and Integrated Models for Demo-Economic Impact Analysis-an Empirical Comparison

Table 7 Long-Run Total Expenditure Impacts, 1990-91 to 1999 $-00$

\begin{tabular}{lrrrr}
\hline Year & Output & \multicolumn{1}{c}{ GSP } & Wages & Employment \\
\hline $1990-91$ & $4,338.13$ & $1,864.59$ & 976.76 & 66.61 \\
$1991-92$ & 887.27 & 400.69 & 316.48 & 32.33 \\
$1992-93$ & 847.64 & 378.23 & 201.85 & 14.35 \\
$1993-94$ & 810.12 & 358.52 & 190.29 & 13.55 \\
$1994-95$ & 739.09 & 323.52 & 172.12 & 12.41 \\
$1995-96$ & 637.98 & 275.09 & 147.01 & 10.75 \\
$1996-97$ & 515.82 & 217.50 & 117.10 & 8.72 \\
$1997-98$ & 383.89 & 156.04 & 85.06 & 6.48 \\
$1998-99$ & 253.98 & 96.15 & 53.74 & 4.25 \\
$1999-00$ & 136.53 & 42.62 & 25.60 & 2.20 \\
\hline Total & $9,550.45$ & $4,112.95$ & $2,286.01$ & 171.65 \\
Multiplier & 4.52 & 4.74 & 4.52 & 3.72 \\
\hline Dollar values in $1985-86$ millions AUD, employment in thousands.
\end{tabular}

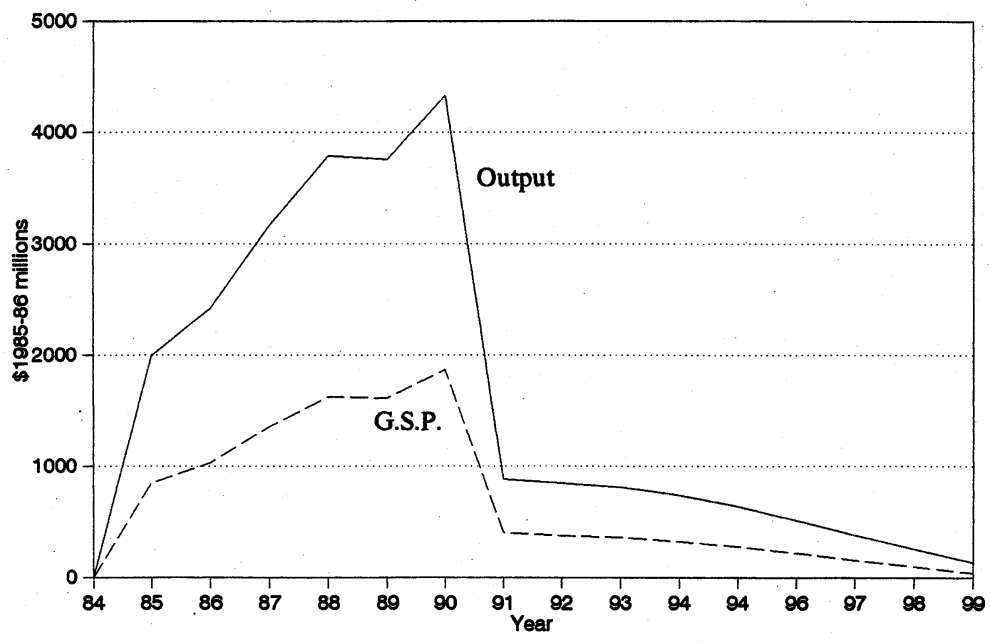

Figure 3. Gross Output and Gross State Product

growth rate dropped to 3.8 per cent. The lag coefficients, which also determine the rate of decline as shown in West (1994), are also relatively small but correspond with empirical evidence. The decline in gross output is also exaggerated because of the double counting involved.

Figure 4 gives a similar picture for wages and salaries, but the rate of decline is not as great. it also shows the effect on total and disposable income. The increased production levels (as a result of tourist activity) gives rise to additional non-wage income. After 


\section{West}

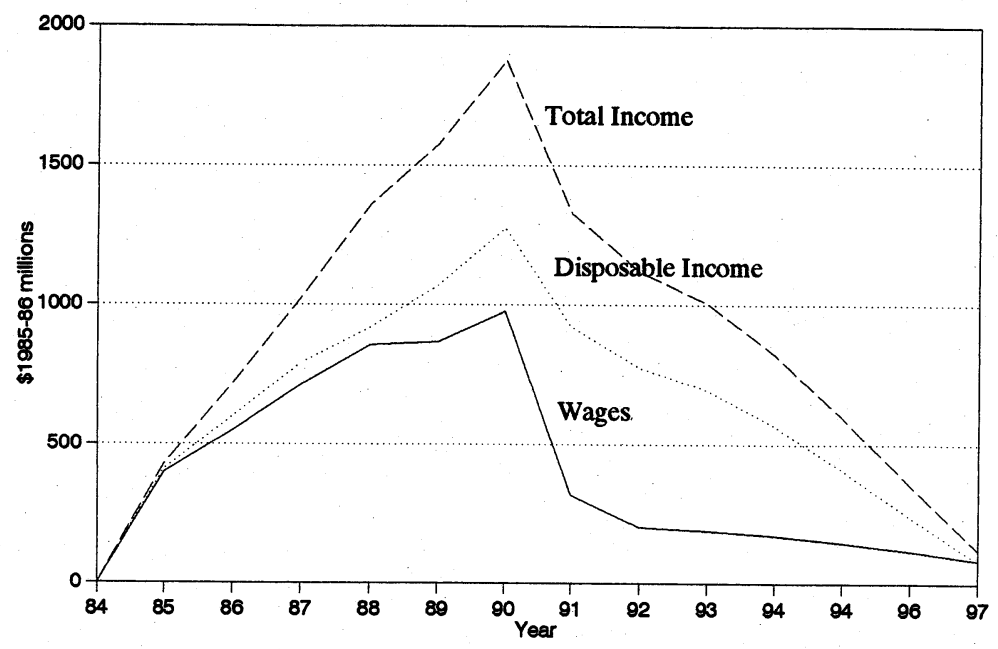

Figure 4. Household Income

adjusting the two income components for income taxes and other taxes and deductions, disposable income can be calculated. Although total and disposable income follow wages and salaries, they take longer to adjust after the tourist expenditures cease.

Figure 5 shows the changes in total employment and labour force. Employment rises immediately in response to the increased tourist activity, but the labour force is slower to react. Thus unemployment levels will initially decline. However, by 1989-90 and 1990-91, the labour force (in-migration) has overreacted to the stimulus, and unemployment starts rising. After the initial impacts cease, employment levels drop quickly but the labour force again takes time to react (through out-migration), and it is not until 1997-98 that it returns to the same level as employment. In the long term, the change in labour force will fluctuate about the change in total employment until equilibrium is again restored.

\footnotetext{
1. The model must be run twice in any application; first without the exogenous shocks to obtain the base level projections and second with the exogenous shocks. The difference provides a measure of the impact on the economy. If $x$ and $z$ refer to endogenous and exogenous variables respectively, 0 the initial state and $d$ the vector of injection, then the solution can be expressed in the general form as :

$\mathrm{t}=0 \quad f^{0}\left(x_{0} ; z_{0}\right)$

$\mathrm{t}=1 \quad f^{1}\left(x_{0} ; z_{0}, z_{1}+d_{1}\right)-f^{1}\left(x_{0} ; z_{0}, z_{1}\right)$

$\mathrm{t}=2 f^{2}\left(x_{0} ; z_{0}, z_{1}+d_{1}, z_{2}+d_{2}\right)-f^{2}\left(x_{0} ; z_{0}, z_{1}, z_{2}\right)$

!

$\mathrm{t}=\mathrm{k} \quad f^{\mathrm{k}}\left(x_{0} ; z_{0}, z_{1}+d_{1}, z_{2}+d_{2}, \ldots, z_{k}+d_{k}\right)-f^{\mathrm{k}}\left(x_{0} ; z_{0}, z_{1}, z_{2}, \ldots, z_{k}\right)$

and then after the shocks cease

$\mathrm{t}=\mathrm{m} f^{\mathrm{m}}\left(x_{0} ; z_{0}, z_{1}+d_{1}, \ldots, z_{k}+d_{k}, z_{k+1}, \ldots, z_{m}\right)-f^{m}\left(x_{0} ; z_{0}, z_{1}, z_{2}, \ldots, z_{\mathrm{m}}\right)$

The rate of decline depends on the relative sizes of $z$ and $d$, and also the length of the lag structure in the econometric model (one year). The lag coefficients are all small (less than 0.4 ) and become negligible after 3 or 4 periods.
} 


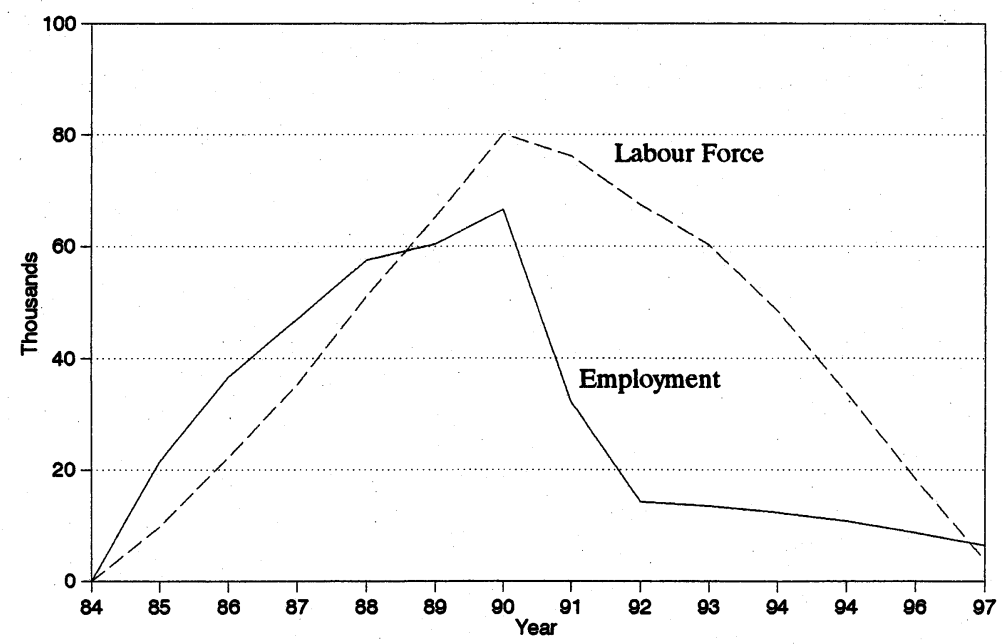

Figure 5. Employment and Labour Force

\section{Summary and Conclusions}

Input-output analysis is still the most widely used technique for regional impact analysis in Australia. The structure is ideal for these type of studies, but that is not to say that the model cannot be improved. The main limitations are the static and linearity properties.

The integrated model provides one avenue for improving the performance of the inputoutput model in impact situations. It partially removes the linearity assumption, particularly with respect to the household sector which is the main concern, and structures the model within a dynamic framework. The benefits are two-fold; the folw-on effects are determined in part by marginal rather than average relationships, and the temporal distribution of the impacts are taken into account. Both factors should produce more reliable estimates in an impact situation.

A direct comparison of the results from the simple input-output model and the integrated model shows the following results. Firstly, from a static (short-run) viewpoint, the aggregated impacts on output, value added, wages and salaries, and employment will be less in the integrated model. This is because the inputs into the production system are governed by marginal relationships rather than average relationships, with other factors such as in or out migration not having time to adjust to the initial stimulus.

However, even though the aggregate flow-ons tend to be less in the integrated model, the distribution of those flow-ons across the industrial sectors is not so clear-cut. Generally speaking, the flow-ons tend to be redistributed from the service type industries, because service industries can often increase output within existing input resources, at least in the 
short term, to the manufacturing type industries which have more rigid production structures.

Secondly, when it comes to viewing the temporal distributions of the flow-ons, a different story unfolds. The input-output model misses out on subsequent flow-through effects to the economy in later time periods through demographic adjustments, and the integrated model demonstrates that these can be quite substantial and take several years (up to a decade in the example used in this paper) to wash out. This can result in multiplier effects of double or more those estimated with a static model. Similar results have been obtained with other integrated models, e. g. the Washington Projection and Simulation Model (Conway (1990)). Although many analysts have a reasonable feel for the size of the short-run multiplier effects, there appears to be little knowledge about the size of the dynamic multiplier effects, and this could become a more important issue in the future.

In conclusion, the integrated model is a viable alternative and improvement on the conventional input-output model. The results are consistent with the static input-output model and conform to expectations about how the economy responds in real impact situations. The integrated model will continue to be developed and used in the Queensland regional modelling environment.

\section{References}

Archer, B. H., 1977, Tourism multipliers : the state of the art, Bangor Occasional Papers in Economics, No. 11, University of Wales Press, Cardiff.

Batey, P. W. J. and M. Madden, 1981, Demographic-economic forecasting within an activitycommodity framework : some theoretical considerations and empirical results, Environment and Planning $A$, vol. 13, 159-178.

Batey, P. W. J., M. Madden and M. J. Weeks, 1987, Household income and expenditure in extended input-output models : a comparative theoretical and empirical analysis, Journal of Regional Science, vol. 27, 341-356.

Bulmer-Thomas, V., 1982, Input-Output Analysis in Developing Countries, Wiley, New York. Conway Jr., R. S., 1990, The Washington projection and simulation model : a regional interindustry econometric model, International Regional Science Review, vol. 13, 141-165.

Fletcher, J. E., 1989, Input-output analysis and tourism impact studies, Annals of Tourism Research, vol. 16 (No. 4), 514-529.

Government Statistician's Office, 1990, Experimental Input-Output Tables Queensland 1985 -86 , Brisbane, Government Statistician's Office.

Hundloe, T., S. Droml, S. Shaw, J. Trigger, G. McDonald, R. Jensen and G. West, 1981, Proposed Cairns Section of the Great Barrier Reef Marine Park : Some Economic Characteristics and Multipliers, Institute of Applied social Research, Griffith University, 
Input-Output and Integrated Models for Demo-Economic Impact Analysis-an Empirical Comparison

Queensland.

Powell, R., B. Davidson, J. Hunter, F. Lynn, M. McGovern and A. Westmore, 1987, The Impact of Tourism Demand on the Coffs Harbour Local Government Area in 1984-85, North Coast Regional Office, Department of Continuing Education, University of New England, Coffs Harbour.

West, G. R., 1991, A Queensland input-output econometric model : an overview, Australian Economic Papers, vol. 30 (No. 57), 221-240.

West, G. R., 1994, The Queensland impact and projection model : the household sector, Economic Systems Research, vol. 6, 363-383.

West, G. R. and B. A. Bayne, 1990, Visitor Analysis Expenditure Model : An Economic Assessment Modelling System of Tourism Activity in Queensland, Queensland Tourist and Travel Corporation, Brisbane. 